\title{
ЛИНГВИСТИЧЕСКОЕ ОБРАЗОВАНИЕ
}

УДК 378

DOI 10.23951/2307-6127-2021-3-124-131

\section{ФОРМИРОВАНИЕ КОММУНИКАТИВНОЙ КОМПЕТЕНЦИИ СТУДЕНТОВ-БАКАЛАВРОВ ПРИ ИЗУЧЕНИИ КУРСА «РЕЧЕВАЯ КУЛЬТУРА ДЕФЕКТОЛОГА» (НА МАТЕРИАЛЕ СТИЛЕВОЙ ДИФФЕРЕНЦИАЦИИ ЯЗЫКА)}

\section{T. А. Бочкарева}

Саратовский государственный университет, Саратов

Актуальность исследования определяется необходимостью устранения двух видов противоречий в образовательном процессе высшей школы: 1) между уровнем сформированности коммуникативной компетенции выпускников школ и требованиями, предъявляемыми к студентам-бакалаврам; 2) между необходимостью внедрения компетентностного подхода и отсутствием единых представлений о понятийном аппарате новой парадигмы, методических средствах ее обеспечения применительно к разным компетенциям и компетентностям.

Цель исследования - разработка методической модели для формирования коммуникативной компетенции студентов-бакалавров при изучении курса «Речевая культура дефектолога» (на материале стилевой дифференциации языка).

В основе разрабатываемой компетентностной методической модели - концепция типологизации материала на всех выделяемых уровнях: формальном, содержательном, прагматическом, организационно-технологическом, оценочном и прогностическом. Раскрывается содержание каждого уровня. Применительно к каждому уровню выделяются ведущие формируемые компоненты коммуникативной компетенции: языковой, дискурсивно-стилистический, риторико-прагматический и этикетно-речевой.

В результате делается вывод о значимости разработки компетентностной методической модели в расширении педагогического инструментария компетентностного подхода. Отмечается возможность применения данной модели для повышения уровня коммуникативной компетенции студентов не только в ходе преподавания «Речевой культуры дефектолога», но и других дисциплин лингвистического цикла. Указывается, что разработанная модель может способствовать устранению выделенных противоречий образовательного процесса. В итоге намечаются перспективы дальнейших исследований.

Ключевые слова: коммуникативная компетенция, образовательная модель, кониепция образовательной модели, параметры образовательной модели, функциональностилевая дифференциачия языка.

Переход от знаниево-центристской парадигмы к гуманистической, компетентностной объективное состояние современного педагогического процесса, актуализированное новыми запросами общества к подготовке специалистов самых разных профилей, в том числе и к педагогам-дефектологам: логопедам, коррекционным педагогам, специальным психологам.

Актуальность исследования определяется необходимостью устранения двух видов противоречий в образовательном процессе высшей школы: 1) между уровнем сформированности коммуникативной компетенции выпускников школ и требованиями, предъявляемыми к 
студентам-бакалаврам; 2) между необходимостью внедрения компетентностного подхода и отсутствием единых представлений о понятийном аппарате новой парадигмы, методических средствах ее обеспечения применительно к разным компетенциям и компетентностям.

Заметим, что понятийный аппарат новой образовательной парадигмы до сих пор не имеет однозначного терминологического базиса и ключевые понятия компетентностного подхода «компетенция» и «компетентность» не являются исключением. Нет единства и в выделении состава компетенций, их содержательных и формальных аспектов. Методический инструментарий компетентностного подхода также нуждается в дальнейшей разработке. До сих пор существуют проблемы оценки уровня компетенций $[1,2]$. Не составляет исключения в этом смысле и коммуникативная компетенция, формированию которой посвящена данная статья.

Различные трактовки дефиниций «компетенция» и «компетентность» представлены в работах Э. Г. Азимова, А. Н. Щукина [3]; В. И. Байденко [4]; J. Kohler [5], С. Б. Серяковой [6], Е. Г. Татура [7]; Ю. В. Фролова, Д. А. Махотина [8] и др. Представляется, что в настоящее время общепризнанным можно считать лишь разделение этих понятий и их несинонимичное употребление.

Наиболее обоснованной мы считаем точку зрения И. А. Зимней, определяющей компетенции как задаваемое извне и осваиваемое субъектом содержание учебного процесса. Компетентность же - интегративное личностное качество человека, результат образовательного процесса, формирующееся на базе и фундаменте компетенций» [9, с. 9-11]. Именно данной трактовки рассматриваемых понятий мы придерживаемся в работе.

Среди ключевых образовательных компетенций обычно выделяются 7 групп: ценностно-смысловые, общекультурные, учебно-познавательные, информационные, коммуникативные, социально-трудовые и компетенции личностного самосовершенствования [10].

В сфере проблематики работы находится коммуникативная компетенция, содержание которой достаточно полно определил М. Р. Львов: «Коммуникативная компетенция - термин, обозначающий знание языка (родного и неродного), его фонетики, лексики, грамматики, стилистики, культуры речи, владение этими средствами языка и механизмами речи - говорения, аудирования, чтения, письма - в пределах социальных, профессиональных, культурных потребностей человека» [11, с. 92-93]. Уже в самом определении видна возможность выделения нескольких компонентов компетенции, учитывающих собственно языковые аспекты, прагматический, дискурсивный и т. д.

Наиболее близка нашим целям практико-ориентированная классификация компонентов коммуникативной компетенции, предложенная М. В. Стуриковой. Она выделяет языковой, дискурсивно-стилистический, риторико-прагматический и этикетно-речевой компоненты [12].

Именно в рассмотренных терминологических значениях указанные термины формируют понятийный аппарат работы.

Собственный многолетний опыт преподавания лингвистических дисциплин на первом курсе факультета психолого-педагогического и специального образования, а также опыт других педагогов, отраженный в многочисленных публикациях, свидетельствует о недостаточности уровня лингвистической подготовки выпускников школ, поступающих на педагогические специальности [13].

Первокурсники не понимают разницы между письменной и устной формами речи, имеют поверхностное представление о стилевой дифференциации языка, что приводит к многочисленным стилевым нарушениям, допускают лексические, грамматические, орфографические, пунктуационные ошибки в количествах, не соотносимых с полученными высо- 
кими баллами ЕГЭ. Неким нонсенсом выглядит стабильный процент (около 16 \% от общего количества ошибок, по нашим данным, данным А. С. Яровой, специфических ошибок письма, дисграфических в работах будущих дефектологов) [14].

Таким образом, существует явное противоречие между уровнем сформированности коммуникативной компетенции выпускников школ и требованиями, предъявляемыми к студентам-бакалаврам.

Цель данного исследования - разработка методической модели для формирования коммуникативной компетенции студентов-бакалавров при изучении курса «Речевая культура дефектолога» (на материале стилевой дифференциации языка).

Формирование коммуникативной компетенции - основа формирования профессиональной компетентности будущих специалистов-логопедов, коррекционных педагогов, специальных психологов в ее универсальной (владение государственным языком) и собственно профессиональной (диагностической, коррекционно-развивающей, консультативной и др.) составляющих.

Дисциплина «Речевая культура дефектолога» Б1.0.07 входит в обязательную часть блока Б1.0 «Дисциплины (модули)» учебного плана ООП и изучается на первом курсе. Направление подготовки бакалавриата 44.03.03 «Специальное (дефектологическое) образование», профили «Логопедия», «Специальная психология», «Олигофренопедагогика», «Тифлопедагогика».

Базовую часть курса составляет изучение функционально-стилевой дифференциации современного русского литературного языка.

Обоснуем предлагаемую методическую модель ее изучения, способствующую, на наш взгляд, разноаспектному формированию коммуникативной компетенции.

В основе методической модели - конщепщия типологизащии материала на всех выделяемых уровнях: формальном, содержательном, прагматическом, организационно-технологическом, оценочном и прогностическом. Применительно к каждому уровню выделяются ведущие формируемые компоненты коммуникативной компетенции: языковой, дискурсивно-стилистический, риторико-прагматический и этикетно-речевой.

Согласно данной концепции, каждый стиль $c$ формальной точки зрения мы рассматриваем как набор типичных языковых средств и правил их употребления в зависимости от одних и тех же прагматических факторов: цели, адресата и сферы функционирования (ведущие формируемые компоненты: языковой, риторико-прагматический). Рассмотрение каждого стиля происходит с учетом выделения следующих типичных формальных параметров: жанрового разнообразия текстов каждого стиля; качеств речи, языковых средств их реализации (на всех уровнях языка); композиционных особенностей текстов (ведущий формируемый компонент дискурсивно-стилистический).

На содержательном уровне рассматриваются типичные языковые черты каждого языкового уровня каждого функционального стиля (ведущий формируемый компонент языковой).

С точки зрения прагматики употребление тех или иных языковых средств «привязывается» к типичным ситуациям официально-делового, научного, бытового и т. д. общения (ведущие риторико-прагматический и дискурсивно-стилистический компоненты).

Особенностью типологизации на организационно-технологическом уровне мы считаем траекторию изучения материала от простого к сложному: от действия по образцу к творческому действию, от совместного действия преподаватель-студент к самостоятельному действию; от понимания чужих текстов и их верифицирования к продуцированию собственных текстов; использование в качестве учебного материала при изучении каждого функци- 
онального стиля текстового, дискурсивного контента, организованного по законам стиля и нарушающего эти законы (ведущие дискурсивно-стилистический, этикетно-речевой компоненты).

Оиеночный уровень представлен унифицированными оценочными качественными характеристиками, соответствующими низкому, среднему и высокому уровням сформированности компонентов коммуникативной компетенции. Примерные уровни сформированности коммуникативной компетенции и их качественная характеристика представлены в таблице.

\section{Примернье уровни сформированности коммуникативной компетенции и их качественные} характеристики для стилевой дифференциации языка

\section{А) Языковой компонент коммуникативной компетенции}

\begin{tabular}{|c|c|c|}
\hline Низкий уровень & Средний уровень & Высокий уровень \\
\hline Знает: отдельные средства & Знает: основные средства & Знает: средства языковой репре- \\
языковой репрезентации стиля; & языковой репрезентации стиля; & зентации стиля в полном объеме; \\
умеет: выделять отдельные & умеет: выделять основные & умеет: выделять все типичные \\
языковые средства в текстах, & языковые средства в текстах, & языковые средства в текстах, \\
находить отдельные стилевые & находить основные стилевые & находить все стилевые несоответ- \\
несоответствия; & несоответствия; & ствия; \\
владеет: слабо владеет навыками & владеет: навыками правильного & владеет: навыками правильного \\
правильного языкового оформле- & языкового оформления текстов & языкового оформления текстов \\
ния текстов определенного стиля & определенного стиля с небольши- & определенного стиля в полном \\
& ми нарушениями & объеме \\
\hline
\end{tabular}

Б) Дискурсивно-стилистический компонент коммуникативной компетенции

\begin{tabular}{|c|c|c|}
\hline Низкий уровень & Средний уровень & Высокий уровень \\
\hline знает: не знает особенности & Знает: основные черты стилевого & Знает: специфику дискурса \\
дискурса каждого стиля, имеет & дискурса, может определить & каждого стиля в полном объеме, \\
отдаленное представление о & несколько типичных стилевых & различия устной и письменной \\
стилевых жанрах, не может & жанров, знает основные различия & формы реализации; \\
определить жанр текста, не & устной и письменной формы их & умеет: различать дискурсивные \\
продуцирует тексты разных & реализации; & проявления всех стилей; \\
жанров, не представляет разли- & умеет: различать дискурсивные & владеет: жанровым регистром \\
чия устной и письменной форм & стилевые проявления трех-четы- & каждого стиля в полном объеме; \\
презентации материала; & рех стилей; \\
умеет: различать дискурсивные & способен активно им пользовать- \\
стилевые проявления одного- & владее: навыками продуцирова- & ся как в устной, так и в письмен- \\
двух стилей; & ния основных жанров каждого & ной формах \\
владеет: навыками продуцирова- & стиля & \\
ния текстов одного-двух жанров & & \\
\hline
\end{tabular}

В) Риторико-прагматический компонент коммуникативной компетенции

\begin{tabular}{|c|c|c|}
\hline Низкий уровень & Средний уровень & Высокий уровень \\
\hline $\begin{array}{c}\text { 3нает: отдельные типовые } \\
\text { ситуации общения, отдельные } \\
\text { речевые жанры отдельных } \\
\text { стилей; } \\
\text { умеет: не умеет определять } \\
\text { функциональный стиль, жанр в } \\
\text { соответствии с речевой ситуа- } \\
\text { цией; } \\
\text { владеет: не владеет навыком } \\
\text { выбирать стиль, жанр в соответ- } \\
\text { ствии с ситуацией общения }\end{array}$ & $\begin{array}{c}\text { 3нает: отдельные типовые } \\
\text { ситуации общения, уместный } \\
\text { стиль, жанры, их основные } \\
\text { особенности; } \\
\text { умеет: не всегда правильно } \\
\text { определяет функциональный } \\
\text { стиль, жанр в соответствии с } \\
\text { речевой ситуацией; } \\
\text { владеет: навыком выбора стиля, } \\
\text { жанра в зависимости от прагма- } \\
\text { тических условий не в полном } \\
\text { объеме }\end{array}$ & $\begin{array}{c}\text { 3нает: все типовые ситуации } \\
\text { общения, уместный стиль, жанр, } \\
\text { его основные особенности; } \\
\text { умеет: правильно определить } \\
\text { соответствие стиля, жанра } \\
\text { ситуации общения; } \\
\text { владеет: навыками выбора стиля, } \\
\text { жанра в зависимости от прагм- } \\
\text { тических условий в полном } \\
\text { объеме }\end{array}$ \\
\hline
\end{tabular}




\begin{tabular}{|c|c|c|}
\hline \multicolumn{3}{|c|}{ Г) Этикетно-речевой компонент коммуникативной компетенцуии } \\
\hline Низкий уровень & Средний уровень & Высокий уровень \\
\hline $\begin{array}{c}\text { Знает: не знает правил этикета и } \\
\text { их специфической стилевой } \\
\text { реализации; } \\
\text { умеет: не умеет выделять этикет- } \\
\text { ные формулы в чужой речи; } \\
\text { владеет: не владеет этической } \\
\text { составляющей речевой культуры, } \\
\text { ее стилевыми особенностями }\end{array}$ & $\begin{array}{c}\text { 3нает: отдельные правила этикета } \\
\text { и их специфическую стилевую } \\
\text { реализацию; } \\
\text { умеет: выделять отдельные } \\
\text { этикетные формулы в чужой } \\
\text { речи; } \\
\text { владеет: владеет основным } \\
\text { этикетным регистром, его } \\
\text { стилевыми особенностями }\end{array}$ & $\begin{array}{c}\text { 3нает: все правила этикета и их } \\
\text { специфическую стилевую } \\
\text { реализацию; } \\
\text { умеет: в полном объеме анализи- } \\
\text { ровать чужую речь на предмет } \\
\text { соответствия этикету; выделяет } \\
\text { все этикетные формулы; } \\
\text { владеет: в полном объеме владеет } \\
\text { этической составляющей речевой } \\
\text { культуры, ее стилевыми особен- } \\
\text { ностями. Уместно и целесообраз- } \\
\text { но употребляет этикетные } \\
\text { формулы в разных ситуациях } \\
\text { общения }\end{array}$ \\
\hline
\end{tabular}

Прогностический уровень - сформированность всех компонентов коммуникативной компетенции, готовность свободно, уместно и целесообразно использовать каждый языковой стиль в соответствующей жанровой форме адекватно ситуации общения с соблюдением языковых норм и норм речевого этикета.

Таким образом, была разработана методическая модель для формирования коммуникативной компетенции в курсе «Речевая культура дефектолога» на материале базового блока курса - стилевой дифференциации языка. Определена ее концепция, выделены ее уровни и компоненты коммуникативной компетенции, формируемые на каждом уровне.

Результаты работы внедрены в практику преподавания «Речевой культуры дефектолога» на факультете психолого-педагогического и специального образования СГУ им. Н. Г. Чернышевского.

Применение данной модели может способствовать, на наш взгляд, успешному формированию коммуникативной компетенции студентов-бакалавров не только в курсе «Речевая культура дефектолога», но и в курсах других дисциплин лингвистического цикла, рассматривающих стилевую дифференциацию языка. Сама же модель - попытка расширить арсенал методических средств реализации компетентностного подхода в формировании коммуникативной компетенции.

Результаты работы могут способствовать снятию обозначенных ранее противоречий в образовательном процессе высшей школы.

Вопросом, требующим дальнейшей разработки в данной проблематике, на наш взгляд, является совершенствование механизмов оценки сформированности отдельных параметров и коммуникативной компетенции в целом.

\section{Список литературы}

1. Игнатьев В. П., Варламова Л. Ф. Об оценке уровня сформированности профессиональной компетенции обучающихся // Научно-педагогическое обозрение (Pedagogical Review). 2020. Вып. 4 (32). С. 62-68.

2. Голуб Г. Б., Коган Е. Я., Фишман И. С. Оценка уровня сформированности ключевых профессиональных компетентностей выпускников УНПО: подходы и процедуры // Вопросы образования. 2008. № 2. С. 161185.

3. Азимов Э. Г., Щукин А. Н. Новый словарь методических терминов и понятий (теория и практика обучения языкам). М.: Изд-во ИКАР. 2009. 448 с.

4. Болонский процесс: результаты обучения и компетентностный подход (книга - приложение) / под науч. ред. В. И. Байденко. М.: Исслед. центр проблем качества подготовки специалистов, 2009. 536 с. 
5. Kohler J. Europäische Qualifikationsrahmen und seine Bedeutung für die Einzelstaatlichen Studiensysteme: European Qualifications Framework for Lifelong Learning (EFQ-LLL) - Qualifications Framework for the European Higher Education Area (QF - EHEA) // Qualität in Studium und Lehre. Stuttgart, 2008. S. 1-26.

6. Серякова С. Б. Компетентностный подход в образовании: от теории к практике // Информация и образование: границы коммуникаций. Горно-Алтайск. 2011. № 3 (11). С. 121-125.

7. Татур Ю. Г. Компетентность в структуре модели качества подготовки специалистов // Высшее образование сегодня. 2004. № 3. С. 10-13.

8. Фролов Ю. В., Махотин Д. А. Компетентностная модель как основа оценки качества подготовки специалистов // Высшее образование сегодня. 2004. №8. С. 34-41.

9. Зимняя И. А. Компетенция и компетентность в контексте компетентностного подхода в образовании // Ученые записки национального общества прикладной лингвистики. 2013. № 4. С. 16-31.

10. Хуторской А. В. Ключевые компетенции и образовательные стандарты. Стенограмма обсуждения доклада A. В. Хуторского в РАO // Интернет-журнал «Эйдос». 2002. 23 апреля. URL: http://www.eidos.ru/ journal/2002/0423-1.htm (дата обращения: 13.02.2021).

11. Львов М. Р. Словарь-справочник по методике преподавания русского языка: пособие для студентов педагогических вузов и колледжей. М.: Академия: Высшая школа, 1999. 272 с.

12. Стурикова М. В. Коммуникативная компетенция: к вопросу о дефиниции и структуре // Инновационные проекты и программы в образовании. 2015. № 6. С. 27-31.

13. Алмазова А. А. Профессиональная лингвистическая подготовка учителей-логопедов в системе высшего образования: автореф. дис. ... д-ра пед. наук. М., 2019. 44 с.

14. Яровая А. С. Коммуникативная компетентность специалистов дефектологического профиля // Auditorium. Электронный научный журнал Курского гос. ун-та. 2020. № 2 (26). URL: https://cyberleninka.ru/article/n/ kommunikativnaya-kompetentnost-spetsialistov-defektologicheskogo-profilya (дата обращения: 13.02.2021).

Бочкарева Татьяна Анатольевна, кандидат филологических наук, доцент, Саратовский государственный университет (ул. Астраханская, 83, Саратов, Россия, 410012).

E-mail: tab1161@mail.ru

Материал поступил в редакциюю 19.02.2021

DOI 10.23951/2307-6127-2021-3-124-131

\section{FORMATION OF BACHELOR STUDENTS' COMMUNICATIVE COMPETENCES WHEN STUDYING THE COURSE "SPEECH CULTURE OF A SPEECH PATHOLOGIST" (ON THE MATERIAL OF STYLE DIFFERENTIATION OF LANGUAGE)}

\section{T. A. Bochkaryova}

\section{Saratov State University, Saratov, Russian Federation}

The author defines the relevance of the study by the need to eliminate two types of contradictions in the educational process of higher education: 1) between the level of formation of the communicative competence of school graduates and the requirements for bachelor students; 2) between the need to introduce a competency-based approach and the lack of shared sense about the conceptual apparatus of the new paradigm, methodological means of its provision in relation to different competences and competencies.

The purpose of this study is to develop a methodological model of the formation of bachelor students' communicative competence while studying the course "Speech culture of a speech pathologist" (based on the material of style differentiation of the language).

The basis of the developed competence-based methodological model is the concept of classification of the material at all distinguished levels: formal, substantive, pragmatic, organizational and technological, evaluative and prognostic. The author reveals the content of each level and identifies the leading formed components of communicative competence for 
each of them: linguistic, discursive and stylistic, rhetorical and pragmatic, etiquette and speech.

As a result, the author concludes about the importance of developing a competence-based methodological model in expanding the pedagogical tools of the competence-based approach. The researcher notes the possibility of using this model to increase the level of communicative competence of students not only in the course of teaching "Speech culture of a speech pathologist", but in other disciplines of the linguistic cycle. The author points out that the developed model can help eliminate the identified contradictions in educational process. In conclusion, the researcher outlines the prospects for further research.

Keywords: Communicative competence, educational model, educational model, characteristics of the educational model, functional and style differentiation of the language.

\section{References}

1. Ignat'ev V. P., Varlamova L. F. Ob otsenke urovnya sformirovannosti professional'noy kompetentsii obuchayushchikhsya [On the assessment of the level of formation of students' professional competence]. Nauchnopedagogicheskoye obozreniye - Pedagogical Review, 2020, vol. 4 (32), pp. $62-68$ (in Russian).

2. Golub G. B., Kogan E. Ya., Fishman I. S. Otsenka urovnya sformirovannosti klyuchevykh professional'nykh kompetentnostey vypusknikov UNPO: podxody i protsedury [Assessment of the level of formation of key professional competencies of ERPA graduates: approaches and procedures]. Voprosy obrazovaniya-Educational Studies Moscow, 2008, no. 2, pp.161-185 (in Russian).

3. Azimov E. G., Shchukin A. N. Novyy slovar' metodicheskikh terminov i ponyatiy (teoriya i praktika obucheniya yazykam) [New dictionary of methodological terms and concepts (theory and practice of teaching languages)]. Moscow, IKAR Publ., 2009. 448 p. (in Russian).

4. Bolonskiy protsess: rezul'taty obucheniya i kompetentnostnyy podkhod (kniga - prilozheniye) [The Bologna Process: Learning Outcomes and Competence-Based Approach (book - appendix)]. Under the scientific editorship of V. I. Baidenko. Moscow, Issledovatel'skiy tsentr problem kachestva podgotovki spetsialistov Publ., 2009. 536 p. (in Russian).

5. Kohler J. Europäische Qualifikationsrahmen und seine Bedeutung für die Einzelstaatlichen Studiensysteme: European Qualifications Framework for Lifelong Learning (EFQ-LLL) - Qualifications Framework for the European Higher Education Area (QF - EHEA). Qualität in Studium und Lehre. Stuttgart, 2008. Pp. 1-26.

6. Seryakova S. B. Kompetentnostnyy podkhod v obrazovanii: ot teorii k praktike [Competence-based approach in education: from theory to practice]. Informatsiya i obrazovaniye: granitsy kommunikatsiy [Information and education: the boundaries of communications]. Gorno-Altaysk, 2011, no. 3 (11), pp. 121-125 (in Russian).

7. Tatur Yu. G. Kompetentnost' v strukture modeli kachestva podgotovki spetsialistov [Competence in the structure of the quality model of training specialists]. Vy'ssheye obrazovaniye segodnya, 2004, no. 3, pp. 10-13] (in Russian).

8. Frolov Yu. V., Makhotin D. A. Kompetentnostnaya model' kak osnova otsenki kachestva podgotovki spetsialistov [Competence model as a basis for assessing the quality of training specialists]. Vyssheye obrazovaniye segodnya, 2004, no. 8, pp. 34-41 (in Russian).

9. Zimnyaya I. A. Kompetentiya i kompetentnost' $\mathrm{v}$ kontekste kompetentnostnogo podkhoda $\mathrm{v}$ obrazovanii [Competence and competency in the context of the competence-based approach in education]. Uchenye zapiski natsional'nogo obshchestva prikladnoy lingvistiki - Scientific Notes of the National Society of Applied Linguistics, 2013, no. 4, pp. 16-31 (in Russian).

10. Khutorskoy A. V. Klyuchevy'e kompetentsii i obrazovatel'nye standarty. Stenogramma obsuzhdeniya doklada A. V. Khutorskogo v RAO [Key competencies and educational standards. Transcript of the discussion of A. V. Khutorsky in RAE]. Internet-zhurnal "Eydos", 2002, 23 April (in Russian). URL: http://www.eidos.ru/ journal/2002/0423-1.htm (accessed 13 February 2021)].

11. L'vov M. R. Slovar'-spravochnik po metodike prepodavaniya russkogo yazyka: posobiye dlya studentov pedagogicheskikh vuzov i kolledzhey [Dictionary-reference book on the methods of teaching the Russian language: a guide for students of pedagogical universities and colleges]. Moscow, Akademiya: Vysshaya shkola Publ., 1999. 272 p. (in Russian). 
12. Sturikova M. V. Kommunikativnaya kompetentsiya: k voprosu o definitsii i strukture [Communicative competence; to the question of definition and structure]. Innovatsionnye proekty i programmy v obrazovanii, 2015, no. 6 , pp. 27-31 (in Russian).

13. Almazova A. A. Professional'naya lingvisticheskaya podgotovka uchiteley-logopedov v sisteme vysshego obrazovaniya. Avtoref. dis. dokt. ped. nauk [Professional linguistic training of teaching speech therapists in the system of higher education. Abstract of thesis of doct. of ped. sci.]. Moscow, 2019. 44 p. (in Russian).

14. Yarovaya A. S. Kommunikativnaya kompetentnost' spetsialistov defektologicheskogo profilya [Communicative competence of specialists in speech pathology profile]. Auditorium. Elektronnyy nauchnyy zhurnal Kurskogo gosudarstvennogo universiteta - Auditorium. Electronic scientific journal of Kursk State University, 2020, no. 2 (26) (in Russian). URL: https://cyberleninka.ru/article/n/kommunikativnaya-kompetentnost-spetsialistovdefektologicheskogo-profilya (accessed 13 February 2021)].

Bochkaryova T. A., Candidate of Philological Sciences, Associate Professor, Saratov State University (ul. Astrakhanskaya, 83, Saratov, Russian Federation, 410012).

E-mail: tab1161@mail.ru 